\title{
An exploration of national calls to Lifeline Australia: Social support or urgent suicide intervention?
}

\author{
Robert J. Watson \\ Dr John McDonald, \\ Dora C. Pearce \\ University of Ballarat \\ AUSTRALIA
}

\section{Contact Details:}

Robert J. Watson

B.A. (Hons.), (Ph.D. Candidate)

$\mathrm{BSSH}$, University of Ballarat,

PO Box 663, Ballarat, VIC,

Australia, 3353.

Phone: (03) 53279197

Email: rwatson@students.ballarat.edu.au

Associate Professor John McDonald,

B.A. (Hons), Grad. Dip. Ed. Tert. Teaching, Ph.D.

Director of Health Research and Practice,

University of Ballarat,

PO Box 663, Ballarat, VIC,

Australia, 3353.

Phone: (03) 53279745

Email: j.mcdonald@ballarat.edu.au

Fax: (03) 53279745

\section{Dora C. Pearce}

Grad. Dip. Epidemiology, Grad. Dip. Education, MA. Information Technology,

School of Science and Engineering,

University of Ballarat,

PO Box 663, Ballarat, VIC,

Australia, 3353.

Phone; (03) 53279264

Email: dpearce@students.ballarat.edu.au 
An exploration of national calls to Lifeline Australia: social support or urgent suicide intervention? 


\begin{abstract}
Lifeline Australia Inc provides a free 24 hour telephone counselling and referral service to all Australians. The trained telephone counsellors of the service record information on many of their calls in Lifeline's Client Service Management Information System (CSMIS). This paper presents a descriptive summary of a national CSMIS data set, which was compiled during a three month period in 2003. The CSMIS data provided a clear national profile of the callers to the service. The results of this study support the hypothesis that callers are generally seeking social support from the service. The discussion explores the implications of this finding for Lifeline and other generalist counselling and referral services and their capacity to offer suicide intervention to the community.
\end{abstract}


Telephone counselling was first used widely by suicide prevention and crisis intervention services, in the 1960s, as a means of providing immediate and inexpensive access to crisis intervention for those in distress (Lester, 2002). There are now a wide variety of community services that address individuals’ psychological needs via the telephone (Coman, Burrows, \& Evans, 2001). Lifeline’s telephone counselling and referral service grew from humble beginnings in Sydney Australia in 1963, to now be a leading national and international organization in its field. This study presents a descriptive summary of national Lifeline data and examines if it is congruent with the service being a generalist telephone counselling and referral service, which in the main serves people seeking social support rather than acute crisis care such as suicide intervention. Lifeline was established to provide a crisis counselling service (Coman et al., 2001), but if its focus has changed then this role may be jeopardised.

Bobevski and Holgate (1997) suggest that telephone counselling tends to be of three types. The first are the large generalist community agencies that provide 24-hour telephone counselling to the community at large. The Samaritans in Great Britain and Lifeline in Australia were identified as providing such a service by these authors. However, data to support this claim or the claim of Coman et al., (2001) that the Lifeline service now provides ongoing counselling were not provided. Generalist telephone counselling and referral services are said to service very heterogeneous populations (Apsler \& Hoople, 1976). The second type of service provides a very specific telephone counselling service for people with particular needs and specific groups. The third type is health and welfare agencies offering telephone counselling within normal business hours. Lazar and Erera (1998) suggest generalist telephone counselling services fill an important niche in providing social support to the community. The 24-hour, accessible and equitable nature of a generalist telephone counselling service has been claimed to make 
them an interesting case study for the examination of social support (Lazar \& Erera, 1998).

Social support refers to social interactions that are perceived by the recipient to facilitate coping and assist in responding to stress (Letvak, 2002). Social support is thought to reduce the total amount of stress a person experiences as well as to help one cope better when stressed (Bunker et al., 2003; Dalgard, Bjork, \& Tambs 1995; House, Landis, \& Umberson, 2003). Cunningham and Barbee (2000) define a social support network as the people from whom an individual can reasonably expect to receive help in a time of need. Social support has been said to contain emotional, practical, and informative dimensions (Landmark, Strandmark, \& Wahl, 2002). The term social isolation is used in the context of the debate about social support and health status, and may be defined as the absence of satisfying relationships and low level of involvement in community life (Rosenfeld, 1997). Data from long-term, prospective studies suggest that a lack of social relationships constitutes a major risk factor for mortality (House et al., 2003). For example, social isolation has consistently been shown to have an independent causal association with the prognosis of coronary heart disease (Bunker et al., 2003; Hemingway \& Marmot 1999; Salovey \& Rothman, 2003). Two broad categories of support are informal and formal.

Bronfenbrenner (1979) suggested that the social environment was made up of multiple layers of influence, with each defined by its proximity to the individual. The first layer consisted of family, which was seen as the most proximal layer to the individual. The Hierarchical Compensatory Model of Source Utilization also suggests that people seek social support in an ordered way. It posits the search for support begins with the closest informal sources of support such as partners or spouse, where available, before seeking assistance from more formal sources (Cheers, 2000). Telephone counselling may be 
regarded as rather impersonal and a more formal source of social support, thus its calls may reflect a breakdown of the caller's more usual or traditional sources of informal social support.

Lazar and Erera (1998) used generalist telephone counselling for an examination of social support in Israel. Calls from non-married persons (64.7\%) were almost twice those for married persons (35.3\%). Lazar and Erera (1998) argued that this was because nonmarried people had a more acute need for social support. They also found that the helpline was servicing only a small proportion of callers in 'acute crisis'. Such findings are consistent with others (Johnson, 1979; Kliewer, Lepore, Broquet, \& Zuba, 1990; Teare, Garrett, Coughlin, Shanahan, \& Daly, 1995), which report 'help lines’ as basically providing social support to the large majority of their callers, rather than acute crisis care such as suicide intervention. Indeed, Lester (1977) has claimed the crisis has gone out of crisis counselling calls.

This study examined national Lifeline Australia call data from its computerised Client Service Management Information System (CSMIS), to examine the claim that the service is a generalist telephone counselling and referral provider. It was thought that the callers to Lifeline would generally be seeking social support from this service, rather than urgent suicide intervention. However, this paper makes no claim that there are any clear demarcations between the two concepts, as social support can clearly be an element of suicide intervention. Rather, we see the calls to a telephone counselling service as occurring somewhere on a continuum of urgency, with urgent suicide calls anchoring one end of this continuum. 


\section{Method}

\section{Materials}

Lifeline Australia Inc. provided CSMIS cases logged between 01-04-2003 to the 29-062003. Fifty-one Lifeline centres and sub-centres from around Australia contributed to the 90,128 individual cases contained in the data set supplied. The Statistical Package for the Social Sciences (SPSS ${ }^{\circledR}$ 11.5) (SPSS Inc, 2003) was used for the analysis.

\section{Procedure}

The 2003 CSMIS call data for the three month period provided by Lifeline Australia Inc. was imported as a comma delimited text file into an SPSS ${ }^{\circledR} 11.5$ file (SPSS Inc, 2003). Variable labels and codes were then added to the file, based on information supplied by Lifeline Australia Inc and the CSMIS User Manual (Cameron, 2001). A descriptive analysis of selected variables was undertaken. The selected variables were: gender; marital status; caller focus; caller called before and how long they had been calling the service; presenting problem; presence of suicidal thoughts; and caller’s diagnosed mental health status. These variables seem to have potential to provide a profile of the callers to the service that could elucidate the service's community role.

\section{Results}

The CSMIS data set supplied for the project contained 90,128 individual cases and 126 variables. Missing data presented a substantial problem. A number of the columns were devoid of data or contained repeated data and other variables had only a small number of cases. The gender variable indicated 52,481 female (58.2\%), 24,868 (27.6\%) male, and 
12,779 (14.2\%) unidentified callers were recorded. Table 1 presents a breakdown of the CSMIS estimated age groupings, to which exact ages entries were aggregated.

"Table 1 about here"

Caller focus was recorded for 59,730 calls (66.3\% of total valid cases), and miscoded for a further eight cases. Calls focusing on the caller accounted for 51,425 cases (86.1\% of valid cases for the variable), family member 4,012 cases (6.7\%), friend 1,307 (2.2\%), professional capacity 872 (1.5\%), partner or spouse 31(0.1\%), other 2075 (3.5\%) cases.

Marital status was reported for all 90,128 cases. Table 2 presents the frequency and percentage of calls received for each relationship grouping in the CSMIS.

\section{"Table 2 about here"}

CSMIS information for the called before variable was available for 26,506 cases (29\% of total valid cases) (male 8,776; females 17,498; unknown 232). Information was available on how long the caller had been using the service for 18,619 cases (21\% of total valid cases) (males 6,214; female 12,281; unknown gender 124). The how long variable was made up of 1,645 cases ( $8.8 \%$ of cases recorded for the variable) indicating the caller had been calling for a few weeks, 2,187 (11.7\%) calling for a few months, 7,355 (39.5\%) calling for more than a year, and $1,000(5.4 \%)$ as calling for a few months to a year. A total of 6,424 (34.5\%) cases recorded the caller using the service for an unknown time and 18 entries were improperly coded and could not be assigned to a CSMIS grouping for the variable.

CSMIS data for the caller's presenting issue was almost complete $(N=90,110)$. Calls creating the non-counselling CSMIS grouping $(n=20,313)$ consisted of 14,049 cases 
(15.6\% of cases for the issue variable) recorded as being hang up or other noncounselling calls. A further 810 cases were recorded in the CSMIS non-counselling grouping as nuisance, abuse, hoax, and breather calls. Thanks and appreciation type noncounselling calls were recorded for 447 (0.5\%) cases. Figure 1 presents the frequency of calls in each of the 10 CSMIS general (level 1) categories for presenting issues and the total number of calls recorded for each issue.

\section{"Figure 1 about here"}

The CSMIS data indicated that suicidal thoughts were recorded for 2,386 calls (2.6\% of total valid cases). Specific mental health problems were recorded for 7,363 cases $(8.2 \%$ of total valid cases). This figure represents mental health disorders disclosed by the caller to the telephone counsellor as having been diagnosed at some time. It is not the role of telephone counsellors to identify or diagnose a caller's mental health condition. Callers may not wish to share a psychological diagnosis with the telephone counsellor or may be un-diagnosed. Therefore, this figure is likely to be an underestimate of the true number of callers with psychological disorders and diagnosis. A breakdown of the total number of cases for each CSMIS mental health disorder category is presented in Figure 2.

"Figure 2 about here"

\section{Discussion}

The results showed that females contacted the Lifeline telephone counselling and referral service at a considerably greater rate than males. The ages of the callers to the service varied considerably and calls to the service generally were about the caller. Callers 
without a partner or spouse were found to be over-represented in the sample. It was apparent that a large proportion of callers identified as regular callers had been calling the service for some time. Callers with suicidal thoughts only seem to have contributed to a small proportion of all calls to the service. Callers with a variety of mental health disorders contacted the service. The results indicate the service caters to a heterogeneous population. These claims are examined in more detail in the following discussion. These results and others supported the claim that Lifeline a generalist telephone counselling and referral service. The results also supported the hypothesis that callers to the service were generally seeking social support, rather than urgent suicide intervention.

The known proportion of female callers (58.2\%) to the Lifeline service was more than twice the known male proportion of callers (27.6\%). Of the 59,730 calls that had CSMIS caller focus details, 86.1 percent were entered as focusing on the caller. In line with previous reports (Johnston, 1979; Lazar \& Erera, 1998; Teare et al., 1995) of generalist telephone counselling and referral services primarily providing social support to their callers, it was found that single and other non-partnered or non-married callers seemed to be over-represented in Lifeline’s calls. Single, widowed, divorced, and separated people do not have the fundamental informal support of a partner or spouse available to them. Being in a close relationship such as being married would normally be expected to involve receiving social support (Turner \& Marino, 1994). Thus, it seems likely single, widowed, divorced, and separated people would use the more formal Lifeline service with greater frequency than those with the informal support of a partner or spouse.

Further evidence that the Lifeline service is a provider of social support may be inferred from the results for regular callers, which indicated over 29 percent of all calls were from people who had called before. It seems highly possible this figure is a conservative 
estimate of the true proportion of cases that might be labelled as called before, as identification of regular callers by frequently changing counsellors is problematic. For example, the Gladstone Lifeline centre reported $41.4 \%$ of all calls as repeated, while Lifeline have suggested that as few as $14 \%$ of all its calls are from first time callers (Lifeline, 2004). Gladstone is a regional centre situated 550 kilometres north of the State capital Brisbane (Gladstone Area and Promotional Development Ltd, 2003). Of the 18,619 cases recorded as having called before, 57 percent were from callers identified as having called for a few months to more than one year. The results suggest the service is catering for a large proportion of repeat cases, many of whom seem to use the services across an extended period of time. Such a finding would be consistent with these callers adopting the service as a part of their ongoing social support network. This finding supports the claim of Coman et al. (2001) that the Lifeline service has adopted an ongoing counselling role.

The CSMIS caller issue categories provided further evidence that Lifeline is a generalist service and that callers to the service were accessing it for general social support, rather than for urgent suicide interventions. The largest category was for the non-counselling issue, accounting for over 20 percent of the 90,128 cases. The next largest issue grouping was self and society, with 16 percent of all calls. The self and society grouping contains the sub-issues of belonging, discrimination, identity, loneliness, relationships, self confidence, social justice, stigma, gender identity, and sexuality. The self and society counselling call grouping seem to point to its callers being potentially socially isolated from sources of support. This seems true of the next two largest most frequently occurring issues. Health and disability category accounted for 15 percent of all cases. Issues in this category include call issues such as mental health issues, intellectual disability, personal injury, and physical illness. The adjustment and loss category 
accounted for 14 percent of all cases and includes death, illness and disability, relationship breakdown, retirement, role change, separation/divorce, and migration or relocation. The five largest sub-groupings, which made up the major CSMIS issues categories, were: mental disorder (Health \& Disability) $(n=8108)$, loneliness (Self \& Society) ( $n=6086)$, relationships breakdown (Adjustment \& Loss) $(n=5561)$, relationships (Self \& Society) $(n=4075)$, and marriage/partner (Family Challenges) $(n=$ 3409). These five sub groupings accounted for 27,239 calls, or $39 \%$ of all 69,797 designated counselling calls for the period examined. All of these major categories and sub groupings seem to point to possible isolation from informal or formal sources of social support. The proportion of mental health callers, who might also be a group at risk of social isolation in the community, would also seem to fit this profile. The numbers of mental heath callers reported in CSMIS would also indicate support for the claim the service has a prominent role in supporting those with mental health issues (Lifeline Australia, 2002).

Further support for the hypothesis that social support rather than urgent suicide calls dominates the calls to Lifeline may be inferred from the number of cases indicating suicidal thoughts were present. Only 2,386 cases (2.6\% of all valid cases) were recorded as involving suicidal thoughts. This proportion of suicidal thoughts in the CSMIS data matches population estimates that 2.9 percent of the adult population attempt suicide (New York State Department of Health, 1994) or 3.1 percent of people having thoughts of life not being worth living (Thomas, Crawford, Meltzer, \& Lewis, 2002). In Australia 1.9 percent of the population are suggested to be dissatisfied with life, with 0.9 percent regarding life as terrible (Australian Bureau Statistics, 2004). The investigation of CSMIS data suggests that the service is indeed servicing callers who are at risk of being socially isolated. Further, the varied range of ages, caller issues, marital statuses, mental health 
statuses, and caller's focus indicate the service is a generalist telephone counselling service. There was little evidence that the service has a primary role in urgent suicide intervention.

The analysis suggests that the service has evolved from its original role in providing crisis intervention and now seems to be a true generalist service offering ongoing support to its callers. This finding has important implications for this service and perhaps other generalist providers. Lifeline Australia's associated centres have found it impossible to meet the demand from its callers, with many calls going unanswered. Analysis of Lifeline Ballarat's monthly call data suggests around $40 \%$ of calls are not answered. The Ballarat centre is located in a rural region in the western part of the State of Victoria (Watson, 2005). Such over-demand sadly can lead to callers who are in urgent crisis being unable to reach the service in their time of need. Lifeline can be seen by potential callers as a last resort (Watson \& McDonald, 2004). Thus, a failure to reach the service by people who are at high risk of suicide may potentially increase their risk of a suicide attempt, as they may have no where else to turn. The Lifeline Australia service has plans to introduce a system whereby calls can be transferred from a centre with no further capacity to take calls to one with lines that are free. This initiative seems a simple answer to the problem of excess demand. However, it may create further problems and demand for the service, while still not guaranteeing a line will be available when it is needed by callers at high risk of suicide. For example, such a change could conceivably increase the use of the service by regular and managed callers, by redirecting these calls to other centres where their histories and management are not known or recognised. It is clear from the Lifeline call data examined that regular callers already place a large pressure on the service's resources. Even if this problem of increased repeat and managed caller use can be avoided with the new system other problems may be anticipated. 
Lifeline Australia's volunteer counsellors are recruited and trained at a rate that is generally matching the rate at which counsellors leave the service. Kinzel and Nanson (2000) report this problem is not one confined to the Lifeline service. It seems probable that Lifeline’s proposed call diversion system will increase the number of calls taken by a volunteer counsellor during a shift. Busier shifts may then contribute to greater stress levels being experienced by the volunteer telephone counsellor during and after a shift. In support of this contention, it has been reported that the greatest predictor of stress in volunteer telephone counsellors was the total length of time spent on calls per shift (Mishara \& Giroux, 1993). In turn, an increase in stress may lead to more of what Kinzel and Nanson (2000) identify as compassion fatigue. Such fatigue seems to have the potential to result in greater burnout and in higher rates of trained counsellors leaving the service, thus potentially leading to an overall reduction in the capacity of the service to take calls (for more information on burnout in telephone counselling services see, Littlefield \& Koff, 1986; MacKinnon, 1998). A possible solution to deal with callers in urgent suicide situations, which may also assist in reducing the stress levels for Lifeline’s counsellors, could be to have a dedicated suicide line that deals exclusively with high risk acute (urgent) suicide cases. This would remove a potentially highly stress provoking group of callers (Mishara \& Giroux, 1993) from the general Lifeline service. This option would also see the provision of a dedicated service to those in greatest immediate risk of suicide. Such an approach would seem a possible step towards a solution to high risk suicide calls going unanswered, and may also assist in addressing the counsellor drop-out rates of the service.

A further possible step in addressing the over-demand problems would be to deal with the drop out rate of the service. If the drop out rate of trained telephone counsellors were addressed it could directly affect both the over-demand and further reduce the drop out 
rate problems. For example, more trained telephone counsellors available to take shifts may mean centres could then have multiple cover on shifts. At present centres can have trouble filling shifts with a single telephone counsellor and can have lines unattended. Multiple cover on shifts, particularly during the potentially busier times of the day, would conceivably lead to more calls being answered per shift. Multiple cover, in turn, has been shown to reduce the stress levels of the telephone counsellors (Mishara \& Giroux, 1993), which would then have the potential to further reduce drop out rates. The issue of drop out rates in these services is an important one that requires further research.

The general social support role of the Lifeline service is no doubt an important one with possibly unidentified and perhaps covert outcomes. The outcomes of telephone counselling services such as Lifeline supporting socially isolated callers who may be at increased risk of illness, both psychological and physical, and premature death (see Bunker et al., 2003; House et al., 2003,) is at present unclear. A review of telephone counselling information and referral services (Community Services Victoria \& Health Department Victoria, 1988) found that telephone counselling can avert the need for further professional assistance (also see Carver, 1995; Evans, Morgan, \& Hayward, 2000). This may suggests it has a role to play in reducing the strain on other health care providers. Poor social support has been shown to be strongly associated with thoughts of life not being worth living (Thomas et al., 2002). It has also been demonstrated that telephone counselling can alleviate psychological distress (Carver, 1995; Ko \& Lim, 1996). Dealing with caller stress and social isolation before it reaches critical levels may avert potentially more acute crisis situations such as suicide attempts from occurring. The benefits that may accrue to the community and clients by having a service such as Lifeline providing general social support should not be underestimated and seem to warrant further empirical research. 
A limitation of the methodology used by this study was that there were no indications of the severity of the crisis experienced by the caller. For example, calls within the abuse and violence presenting issue category may have the potential to be urgent and life threatening. However, other emergency services such as the police are available and could be called on in such cases. We would argue that the emergency suicide call was the main reason that Lifeline was established. Indeed, the service was established by the Rev. Dr Alan Walker in response to a suicide death. This event was Walker's motivation for establishing a counselling service that could be accessed by phone any time of day or night (Lifeline Australia, 2003; Walker, 1967). Moreover, there can still be a perception that this is the role of the service and that it can be a last resort in such cases (Watson \& McDonald, 2004). For these reasons we anchored the urgent end of the call continuum with the suicide call and used caller suicidal ideation as an indicator of the extent that the service is being used as a suicide crisis line in contrast to a generalist telephone counselling and referral service. Using this approach the results clearly show that the large majority of calls to the service are not for acute suicide intervention. The results clearly show that the service is a generalist service that provides support to varied callers for many reasons.

The results of this study indicate that Lifeline Australia's telephone counselling service appears to be a generalist telephone counselling service with a primary role in providing social support to potentially socially isolated callers. It may be that the Lifeline telephone counselling and referral service needs to decide whether it continues trying to provide both social support and acute suicide intervention. Impending changes to the Lifeline telephone system, that would allow calls to be directed from a busy centre to one that has free counselling lines, could alleviate the existing problems with unmet demand for 
counselling from the service. However, such a change may not help Lifeline deal with the fundamental problem of trained volunteers leaving the service. The proposed change may even increase this problem and would not seem to solve the problem of urgent suicide calls to the service going unanswered. 


\section{References}

APSLER, R., \& HOOPLE, H. (1976) Evaluation of crisis intervention services with anonymous clients. American Journal of Community Psychology, 4, 293-302.

AUSTRALIAN BUREAU OF STATISTICS. (2004). Mental health in Australia: a snapshot. Retrieved November 8, 2004 from http:/www.abs.gov.au/AUSSTATS/abs@.nsf/mf/4824.0.55.001?OpenDocument

BOBEVSKI, I., \& HOLGATE, A. M. (1997). Characteristics of effective telephone counselling skills [Electronic version]. British Journal of Guidance \& Counselling, 25, 239-249.

BRONFENBRENNER, U. (1979). The ecology of human development. Cambridge: Harvard University Press.

BUNKER, S. J., COLQUHOUN, D. M., ESLER, M. D., HICKIE, I. B., HUNT, D., JELINEK. V. M., OLDENBURG, B. F. (2003). Position statement "stress" and coronary heart disease: psychosocial risk factors [Electronic version]. Medical Journal of Australia, 178, 272-276.

CAMERON, L. (2001). Lifeline Australia telephone counselling CSMIS user manual. Brisbane: Lifeline Brisbane.

CARVER. F. A. (1995). Crisis counselling: an exploratory study of outcomes. Canberra: University of Canberra.

CHEERS, B. (2000). Social support in remote areas of Australia. Rural Social Work, 6, 4-16.

COMAN, G. J., BURROWS, G. D., \& EVANS, B. J. (2001). Telephone counselling in Australia: applications and considerations for use. British Journal of Guidance \& Counselling, 29, 247-258.

COMMUNITY SERVICES VICTORIA, \& HEALTH DEPARTMENT VICTORIA. (1988). Review of telephone counselling, information and referral services: final report. Melbourne: Community Service Victoria. 
CUNNINGHAM, M. R., \& BARBEE, A. P. (2000). Social support. In C. Hendrick, \& S. S. Hendrick (Eds.), Close relationships: A sourcebook (pp. 51-84). Thousand Oaks, CA: Sage.

DALGARD, O. S., BJORK, S., \& TAMBS, K. (1995). Social support, negative life events and mental health. British Journal of Psychiatry, 166, 29-34.

EVANS, M. O., MORGAN, G., \& HAYWARD, A. (2000). Crisis telephone consultations for deliberate self-harm patients: how the study groups used the telephone and usual health-care services [Electronic version]. Journal of Mental Health, $\mathbf{9}$, 155-165.

GLADSTONE AREA PROMOTION AND DEVELOPMENT LTD. (2003). The Gladstone Region: be surprised! Retrieved December 23, 2004, from http://www.gladstoneregion.org.au/gladstone.jsp

HEMINGWAY, H., \& MARMOT, M. (1999). Psychosocial factors in the aetiology and prognosis of coronary heart disease: Systematic review of prospective cohort studies [Electronic version]. British Medical Journal, 318, 1460-1468.

HOUSE, J. S., LANDIS, K. R., \& UMBERSON, D. (2003). Social relationships and health. In P. Salovey., \& A. J. Rothman (Eds.). Social Psychology of Health. New York: Psychology Press.

JOHNSTON, R. J. (1979). The homes of callers to a telephone counselling service: towards a mapping of community in the city. New Zealand Geographical Society, 35, 34-40.

KINZEL, A., \& NANSON, J. (2000). Education and debriefing: Strategies for preventing crises in crisis-line volunteers. Crisis, 21, 126-134.

KLIEWER, W.S., LEPORE, S. A., BROQUET, A., \& ZUBA, L. (1990). Developmental and gender differences in anonymous support-seeking: analysis of data from community helpline for children. American Journal of Community Psychology, 18, 333-339

KO, S., \& LIM, H. B. L. (1996). SAGE telephone counselling. Stress Medicine, 12, 261265. 
LANDMARK, B. T., STRANDMARK, M., \& WAHL, A. (2002). Breast cancer and the experience of social support: in-depth interviews of 10 women with newly diagnosed breast cancer [Electronic version]. Journal of Caring Sciences, 16, 216-224.

LAZAR, A., \& ERERA, P. (1998). Telephone helplines as social support. International Social Work, 14, 89-101.

LESTER, D. (1977). The use of the telephone in counselling and crisis intervention. In I. de Sola. Pool (Ed). The social impact of the telephone. Cambridge: MIT Press.

LESTER, D. (Ed.). (2002). Crisis intervention and counselling by telephone ( $2^{\text {nd }} \mathrm{ed}$.). Springfield: Charles C. Thomas.

LETVAK, S. (2002). The importance of social support for rural mental health [Electronic version]. Issues in Mental Health Nursing, 23, 259-261.

LIFELINE AUSTRALIA INC. (2002). Lifeline in mental health: a perspective on the mental health needs of the Australian community. Melbourne: Lifeline Australia Inc.

LIFELINE AUSTRALIA. (2003). Lifeline Australia Website. Retrieved April 14, 2003, from http://www.lifeline.org.au/

LIFELINE AUSTRALIA INC. (2004). Centre Managers Meeting 2004. Paper presented at the Centre Managers Meeting, Sydney, Australia.

LITTLEFIELD, S. N., \& KOFF, S. Z. (1986). Hotlines that burnout: a study of the factors which contribute to the failure of crisis intervention centres. Journal of Health and Human Resources, 8, 278-295.

MACKINNON, C. (1998). Empowered consumers and telephone counselling. Crisis, 19, 21-23.

MISHARA, B., \& GIROUX, G. (1993). The relationship between coping strategies and perceived stress in telephone intervention volunteers at a suicide prevention centre. Suicide and Life-Threatening Behaviour, 23, 221-229. 
NEW YORK STATE DEPARTMENT OF HEALTH. (1994, May). When death is sought: Assisted suicide and euthanasia in the medical context. Retrieved October 8 , 2004 from http:/www.health.state.ny.us/ny.us/nysdoh/provider/death.htm

ROSENFELD, E. (1997) Social support and health status: a literature review. Adelaide: South Australian Community Health Research Unit.

SALOVEY, P., \& ROTHMAN, A. J. (Eds)(2003). Social Psychology of Health. New York: Psychology Press.

SPSS INC. (2003). SPSS for Windows 11.5 (standard version). USA: SPSS Inc.

TEARE, J. F., GARRETT, C. R., COUGHLIN, D. D., SHANAHAN, D.L., \& DALY, D. L. (1995). America's children in crisis; adolescents' requests for support from a national telephone hotline. Journal of Applied Developmental Psychology, 16. 21-33.

THOMAS, H.V., CRAWFORD, M., MELTZER, H., \& LEWIS, G. (2002). Thinking life is not worth living: a population survey of Great Britain. Social Psychiatry \& Psychiatric Epidemiology, 37, 351-356.

TURNER, R. J., \& MARINO, F. (1994). Social support and social structure: a descriptive epidemiology. Journal of Health and Social Behavior, 35, 193-212.

WALKER, A. (1967). The Life Line story: help is as close as the phone. London: Collins.

WATSON, R. J. (2005). Generalist telephone counselling and referral call data as a source of social indicators: a lifeline to social support? Unpublished doctoral dissertation, University of Ballarat, Australia.

WATSON, R. J., \& McDONALD, J. (2004). A rural perspective of telephone counselling and referral. Australian Journal of Primary Health. 10, 97-103. 


\section{Acknowledgments}

The authors wish to thank the Australian Research Council and industry partners

UnitingCare - Lifeline Ballarat and Lifeline Australia Inc. for their valued support. This paper is dedicated to Noeleen and Sam their love and support. 
Table 1

CSMIS caller age groupings

\begin{tabular}{lcc} 
CSMIS Age Group & Number of calls & Percentage \\
\hline $0-14$ & 364 & .4 \\
$15-19$ & 1740 & 1.9 \\
$20-24$ & 4598 & 5.1 \\
$25-34$ & 14509 & 16.1 \\
$35-44$ & 17909 & 19.8 \\
$45-54$ & 14245 & 15.8 \\
$55-64$ & 8573 & 9.5 \\
$65-74$ & 2509 & 2.7 \\
$75-84$ & 924 & 1.0 \\
$85+$ & 283 & .3 \\
Unknown & 24471 & 27.2 \\
\hline Totals & 90128 & 99.8 \\
\hline
\end{tabular}


Table 2

CSMIS Caller Marital Status Data

\begin{tabular}{lrr} 
Relationship & Frequency & Percentage \\
\hline Divorced & 6486 & 7.2 \\
Married & 10764 & 11.9 \\
Partnered & 5313 & 5.9 \\
Separated & 7007 & 7.8 \\
Single & 23112 & 25.6 \\
Widowed & 2901 & 3.2 \\
No Code & 5 & 0.0 \\
Unknown & 34540 & 38.3 \\
\hline Total & 90128 & 100.0 \\
\hline
\end{tabular}




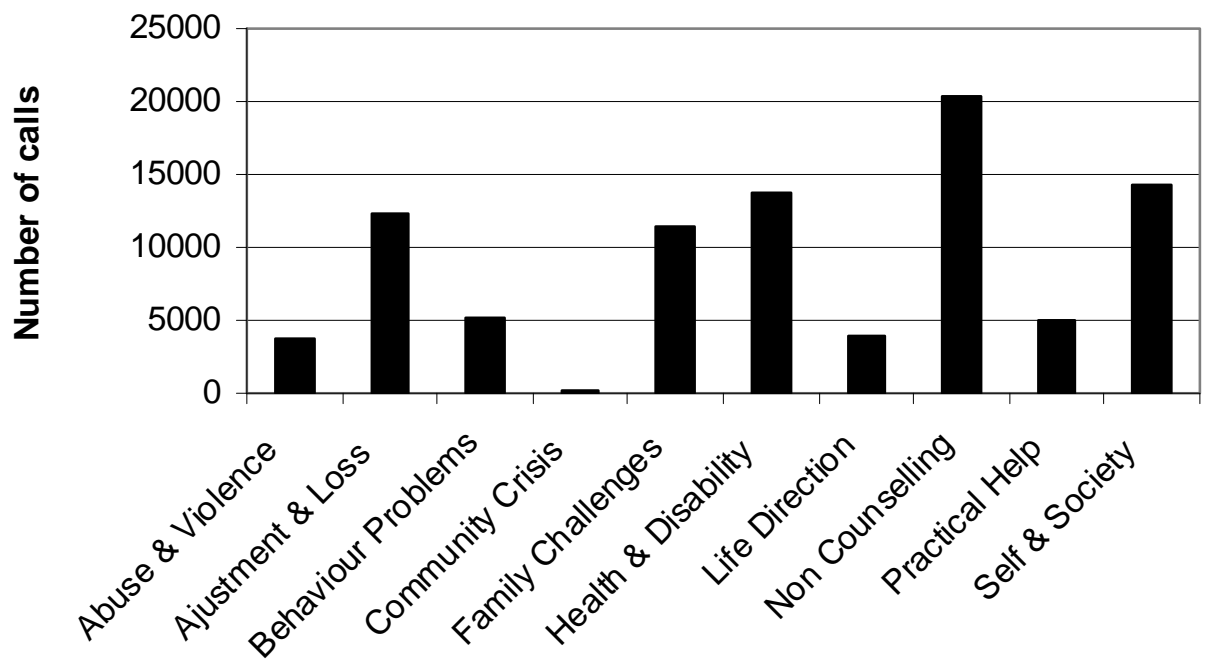

Figure 1. CISMS presenting issue categories and call totals. 


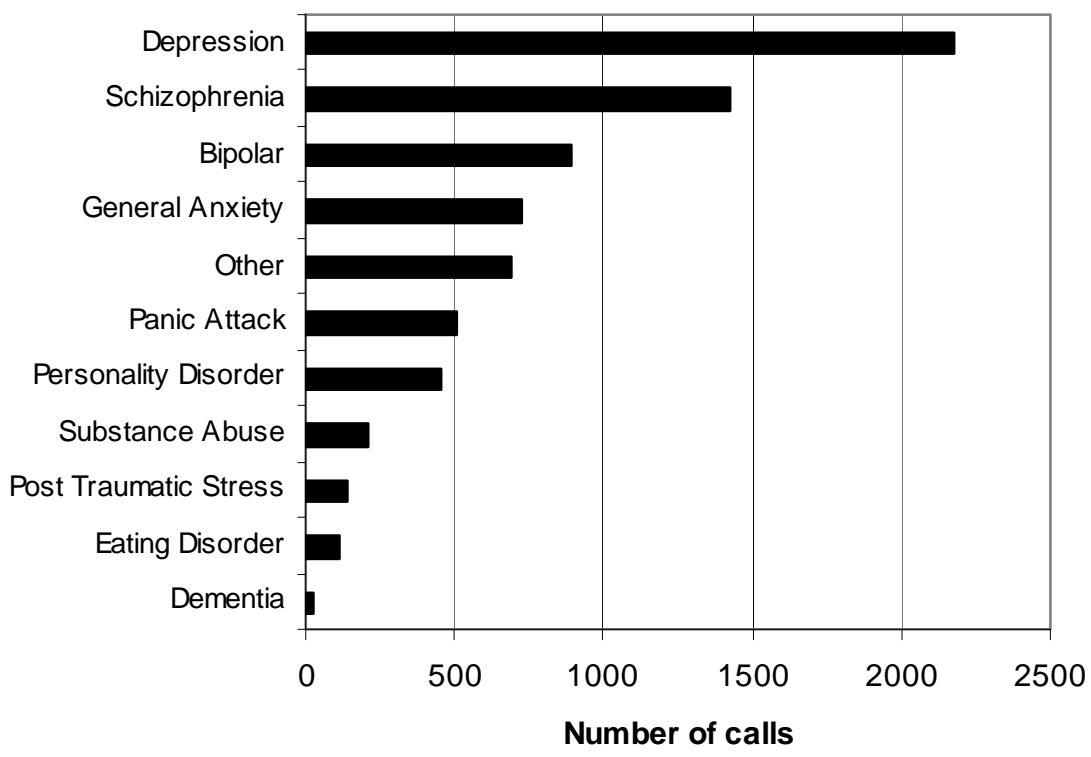

Figure 2. Number of previously diagnosed mental problems reported by callers within each CSMIS mental health category. 